\title{
MJN STRESS AND COPING STRATEGIES DURING CLINICAL PRACTICES AMONG DEGREE NURSING STUDENTS OF A PRIVATE INSTITUTION
}

\author{
Noor Asiah Binti Md. Noor, Rosnida Abu Bakar, Yee Bit-Lian* \\ Open University Malaysia, Jalan Puchong, Petaling Jaya, Selangor, Malaysia \\ *Corresponding Author's Email:yeebl@oum.edu.my
}

\begin{abstract}
Introduction: Nursing students undergoing training in nursing faculty seem to have a higher potential to cope with stress and challenges. This study is to determine stress and coping strategies during clinical practices among degree nursing students of a private institution. Methodology: Descriptive, cross-sectional design in assessing students' stress and sources of stress as well as identify the coping strategies used by students. Total of 122 undergraduate nursing students participated in this research study by using self-reported questionnaire. Results: Majority were female, ages between 31 to 40 years, from semester 4 and with working of experience between 11 to 20 years. Most frequent types of stress found among these students were during taking care of patients are lack of experience and ability in providing nursing care and in making judgment. The lack of knowledge regarding the possible ways to help patients with physio-physio-social concerns and concern about not being trusted or accepted by patients or patients' family. Coping behaviours indicates a statistically significant difference between all the coping behaviours between male and female respondents. Discussion: High level of stress can affect the physical, psychological health of the individual. This may also affect the cognitive process involving memories, recall of knowledge and attention.
\end{abstract}

Keywords: Stress, Coping Behaviour, Contribution Factor, Degree Nursing Students, Private Institution

\section{INTRODUCTION}

The crucial part of nursing education is clinical training, where nursing students begin to develop a health care professional ethics provider and the basic of their nursing competencies. The challenges of clinical practice can be very stressful for students. During clinical practices, nursing students are frequently exposed to various stressors which may directly or indirectly impede their learning and performance. Moreover, the practical components of the program which is important in preparing students to develop into professional nurse role by its nature have made the program even more stressful than other programs (Abdullah, Nahid \& Itedal, 2015). In the learning and teaching process, the Faculty of Nursing and Allied Health Sciences ensures students to have the opportunity to practice the basic skills that they will use during the clinical practice. With a focus on the ward environment that is so vastly different from the classroom environment with its modern equipment, variety of illnesses, the needs of patients, the role of the staff nurses in hospitals, mentor nurses, and nurse instructors who supervise their clinical practice skills together with preparing the nursing students with knowledge and skills. Workload, interpersonal conflicts with friends, inadequate preparation, lack of support from staff and uncertainty concerning treatment are also the causes of stress. The researchers are interested to study the factors influencing stress in nursing students and nurses in the period of the clinical practice with the circumstances as described.

\section{Problem Statement}

During clinical practice, students face many challenges or threats in a dynamic and complex clinical environment, such as how to use high-tech medical equipment, how to maintain good relationships with clinical staff and preceptors, how to manage sudden changes in a patient's condition and how to deal with the demands of patients' relatives. Verbally the students complain regarding the clinical practice including time constraints, the location of clinical attachment and the situation where the students are not allowed to hands on in the procedure of patients. Prolonged experience of stress may have negative impacts on students' clinical learning. It will affect the cognitive process involving memory, recall of knowledge and attention. A great deal 
of stress is encountered by the degree nursing students in the course of adjusting to a rigorous course of clinical practice as they lack sufficient knowledge and skill to perform their duties and to provide adequate care to the patients.

\section{Conceptual Framework}

The conceptual framework developed for the current study is based on Selye $(1974,1976)$, Lazarus \& Folkman (1984), and Rosenbaum (1990). Goff (2011) represented the sources of stress and the coping strategies on degree nursing students. When a stress is perceived as a threat, students are more likely to experience lowest level of satisfaction, motivation, and persistence, performing more poorly, and eventually failing or dropping out. Stress viewed as a challenge may improve motivation, decision-making, coping style, self-confidence, satisfaction, and academic performance. Several factors may impact stress, including demographics, environment with its modern equipment, variety of illnesses, the needs of patients, the role of the staff nurses in hospitals, mentor nurses, and nurse instructors who supervise their clinical practice skills together with preparing the nursing students with knowledge and skills, workload, interpersonal conflicts with friends, inadequate preparation, lack of support from staff and uncertainty concerning treatment.

\section{Literature Review}

Stress among nursing students has increased attention in the literature. Clinical practice fear includes clinical placements, fear of making mistakes and interactions with other staff members. Personal and social sources include financial concerns and the absence of leisure time (Alzayyat \& Al-Gamal, 2014). Meanwhile, coping has been viewed as a stabilizing factor that may assist individuals in maintaining psychosocial adaptation during stressful events. Active or reactive coping responses can be positive or negative, depending on the situation and the content of the response (Singh, Sharma, \& Sharma, 2011).

Abdullah Nahid \& Itedal, (2015) on a retrospective, cross-sectional, descriptive study design reported that the most stressful clinical setting perceived by nursing students were Intensive care unit (ICU), followed by emergency room (ER) and the third stressful area was the surgical units, while the least stressful area was the medical units. Regarding the coping strategies, the researcher found that nursing students commonly used coping strategies and their effectiveness was transference to other activities. The most and least effective coping strategies cited by the participants were avoidance technique. As recommended by Kaneko \& Momino (2015) and Abdullah Nahid \& Itedal, (2015), that faculty teachers and clinical instructors must actively engage with students to give them needed debriefing and guidance.

Labrague (2013) found that stress among the nursing students is similar with Abdullah Nahid \& Itedal, (2015) which were from assignment and workload. Beside that the researcher found emotional symptoms were the most common response to stress. Shiferaw, Anand \& Nemera (2015) found that stress is related to the change of life, personal and work-related and too many changes at one time, whether positive or negative, can overload the capacity of individuals to adapt successfully and cause diseases of one kind or other. The most common stress was from intrapersonal factors. In the study of Khater, Akhu-Zaheya \& Shaban (2014) indicate the cause of the stress of nursing staff and teacher are displayed by Khater, Akhu-Zaheya \& Shaban (2014) were the same as those already examined by Kaneko \& Momino (2015).

Al-Zayyat \& Al-Gamal (2014) found that while taking care of patients, the stress related to teachers and other nursing staff and the stress from assignments and workloads had the highest means among all perceived stress subscale scores among the nursing students. These findings are consistent with previous research studies (Labrague, 2013; Abdullah, Nahid, \& Itedal, 2015).

Singh, Sharma \& Sharma (2011) reported that the students experienced stress due to assignments and workload. A similar result was shown in a study conducted by (Al-Zayyat \& Al-Gamal, 2014; Labrague, 2013; Abdullah, Nahid \& Itedal, 2015) who found that examinations, the intense amount of work, and difficult academic work were the most important source of stress. The researcher also found that stress have both advantages and disadvantages, it depends on how the nursing student will see them and deal with them. Ajibade et al. (2016) found that the situation seems to develop stress to nursing students may lead to some adverse changes in the life of their psychosocial and long-term physical and mental well-being, they can be irritable, showed a lack of concentration, decreased academic performance, poor inter-personal relations, insomnia and absenteeism. Khater, Akhu-Zaheya \& Shaban (2014) made an inference that the common type of stressors perceived by the students were related to 
assignment followed by stress related to patients care and stress from nursing staff and teachers.

\section{METHODOLOGY}

\section{Design}

A descriptive, cross-sectional design was used in assessing students' stress and sources of stress among nursing students as well as identifying the coping strategies used by students.

\section{Sample}

A total of 122-degree nursing students in various academic years of study, of the Nursing Degree Program, in the faculties of nursing in private institution participated in this study.

\section{Research Instrument}

The study used a self-reported questionnaire, which was composed of demographic data, and Perceived Stress Scale (PSS) and a Coping Strategies Inventory (CSI). Demographic data included: age, gender, and years of education and previous nursing experienced. The Perceived Stress Scale (PSS) was developed by Sheu et al. (1997) in order to examine nursing students' stress levels and types of stressors. It consists of 29 items of 5-point Likert scale. The five possible responses range from "never" to "always" and are scored from 0-4. A lower score means lower degrees of stress while the higher score means higher levels of stress. Reliability of the instrument revealed Cronbach's alpha of 0.769-0.938 (Chan et al., 2009; Sheu et al., 2002); and the content validity index was 0.94 (Chan et al., 2009). In the current study, Cronbach's alpha is 0.953. To determine PSS score by following these directions:

First, reverse your scores for questions $4,5,7$, and 8 . On these 4 questions, change the scores like this: $0=4,1=3$, $2=2,3=1,4=0$.

Individual scores on the PSS can range from 0 to 40 with higher scores indicating

higher perceived stress.

Scores ranging from 0-13 would be considered low stress.

Scores ranging from 14-26 would be considered moderate stress.

Scores ranging from 27-40 would be considered high perceived stress.

Coping behavior Inventory (CBI) developed by Sheu et al. (2002) was used to identify nursing students' coping strategies. It consists of nineteen items of 5-point Likerttype $(0=$ never; $1=$ infrequently; $2=$ sometimes; $3=$ frequently; $4=$ always). The nineteen items of the scale are divided into four subscales. Higher scores of each factor indicate more frequent use and greater effectiveness of a certain type of coping behavior. Permission to use both instruments was obtained from authors.

\section{Reliability and Validity}

The Perceived Stress Scale (PSS) questionnaire has been validated by Sheu et al. (2002). The content validity index of the PSS questionnaire was 0.94, thus proved its validity. In this study, the Cronbach's Alpha was 0.953 . Both questionnaires were pilot tested before they were distributed to the participants enrolled in the investigation (Labrague, 2013).

\section{Analysis Data}

Data were analysed using statistical package for social sciences (SPSS) software version 2.0. Descriptive statistics were calculated for every measured variable, in order to evaluate the studied sample. All analysis was shown using a table.

\section{RESULTS}

A complete survey was collected from 122 respondents. The majority of them were female between 31 to 40 years from semester 4 , with working experience 11 to 20 years.

Table 1: Demographic Factors of the Respondents in the research study $(n=122)$

\begin{tabular}{|l|c|c|}
\hline & Frequency & Percent (\%) \\
\hline Gender (Mean = 1.94) & & \\
\hline Male & 7 & 5.7 \\
\hline Female & 115 & 94.3 \\
\hline Age (Mean = 1.89) & & \\
\hline 20 to 30 years & 40 & 32.8 \\
\hline 31 to 40 y ears & 56 & 45.9 \\
\hline 41 and above & 26 & 21.3 \\
\hline Semester (Mean = 1.40) & & \\
\hline Semester 4 & 77 & 63.1 \\
\hline Semester 5 & 41 & 33.6 \\
\hline Semester 6 & 4 & 3.3 \\
\hline Experience (Mean= 1.61) & & \\
\hline 4 to 10 years & 53 & 43.4 \\
\hline 11 to 20 years & 63 & 51.6 \\
\hline More than 20 years & 6 & 5.0 \\
\hline
\end{tabular}


Table 2: Descriptive Statistics of Stress Factors $(n=122)$

\begin{tabular}{|c|c|c|c|c|c|}
\hline I. Stress from taking care of patients & $\begin{array}{c}\text { Never } \\
(\%)\end{array}$ & $\begin{array}{c}\text { Infrequently } \\
(\%)\end{array}$ & $\begin{array}{c}\text { Sometimes } \\
(\%)\end{array}$ & $\begin{array}{l}\text { Frequently } \\
(\%)\end{array}$ & $\begin{array}{c}\text { Always } \\
(\%)\end{array}$ \\
\hline $\begin{array}{l}\text { Lack of experience and ability in providing nursing care and in } \\
\text { making judgments }\end{array}$ & 13.1 & 19.7 & 46.7 & 19.7 & .80 \\
\hline $\begin{array}{l}\text { Do not know how to help patients with physio-psycho-social } \\
\text { problems }\end{array}$ & 15.6 & 19.7 & 44.3 & 19.7 & .80 \\
\hline Unable to reach one's expectations & 7.4 & 22.1 & 51.6 & 18.0 & .80 \\
\hline $\begin{array}{l}\text { Unable to provide appropriate responses to doctors', teachers', } \\
\text { and patients' questions. }\end{array}$ & 15.6 & 27.9 & 37.7 & 18.0 & .80 \\
\hline $\begin{array}{l}\text { Worry about not being trusted or accepted by patients or } \\
\text { patients' family }\end{array}$ & 19.7 & 23.0 & 36.9 & 19.7 & .80 \\
\hline Unable to provide patients with good nursing care & 30.3 & 30.3 & 24.6 & 13.9 & .80 \\
\hline Do not know how to communicate with patients. & 35.2 & 26.2 & 23.0 & 13.9 & 1.6 \\
\hline $\begin{array}{l}\text { Experience difficulties in changing from the role of a student } \\
\text { to that of a nurse }\end{array}$ & 20.5 & 31.1 & 36.1 & 12.3 & 0.0 \\
\hline \multicolumn{6}{|l|}{ II. Stress from assignments and workload. } \\
\hline Worry about bad grades & 2.5 & 5.7 & 32.8 & 33.6 & 25.4 \\
\hline $\begin{array}{l}\text { Experience pressure from the nature and quality of clinical } \\
\text { practice }\end{array}$ & 2.5 & 12.3 & 54.1 & 23.8 & 7.4 \\
\hline $\begin{array}{l}\text { Feel that one's performance does not meet teachers' } \\
\text { expectations }\end{array}$ & 2.5 & 15.6 & 50.0 & 24.6 & 7.4 \\
\hline $\begin{array}{l}\text { Feel that the requirements of clinical practice exceed one's } \\
\text { physical and emotional endurance. }\end{array}$ & 5.7 & 14.8 & 49.2 & 24.6 & 5.7 \\
\hline $\begin{array}{l}\text { Feel that dull and inflexible clinical practice affects one's } \\
\text { family and social life }\end{array}$ & 12.3 & 13.9 & 43.4 & 24.6 & 5.7 \\
\hline \multicolumn{6}{|l|}{ III. Stress from Lack of Professional Knowledge and skills } \\
\hline Unfamiliar with medical history and terms & 16.4 & 22.1 & 44.3 & 15.6 & 1.6 \\
\hline Unfamiliar with professional nursing skills & 18.9 & 30.3 & 36.9 & 12.3 & 1.6 \\
\hline Unfamiliar with patients' diagnoses and treatments. & 18.9 & 26.2 & 42.6 & 9.8 & 2.5 \\
\hline \multicolumn{6}{|l|}{ IV. Stress from the environment } \\
\hline $\begin{array}{l}\text { Feel stressed in the hospital environment where clinical } \\
\text { practice takes place }\end{array}$ & 17.2 & 19.7 & 41.0 & 17.2 & 4.9 \\
\hline Unfamiliar with the ward facilities & 18.0 & 24.6 & 32.8 & 20.5 & 4.1 \\
\hline Feel stressed from the rapid change in patient's condition & 13.1 & 21.3 & 36.1 & 23.8 & 5.7 \\
\hline \multicolumn{6}{|l|}{ V. Stress from peers and daily life } \\
\hline $\begin{array}{l}\text { Experience competition from peers in school and clinical } \\
\text { practice }\end{array}$ & 9.0 & 19.7 & 48.4 & 19.7 & 3.3 \\
\hline $\begin{array}{l}\text { Feel pressure from teachers who evaluate students' } \\
\text { performance by comparison. }\end{array}$ & 7.4 & 24.6 & 41.0 & 24.6 & 2.5 \\
\hline $\begin{array}{l}\text { Feel that clinical practice affects one's involvement in } \\
\text { extracurricular activities }\end{array}$ & 10.7 & 22.1 & 42.6 & 19.7 & 4.9 \\
\hline Cannot get along with other peers in the group. & 28.7 & 23.0 & 32.8 & 13.1 & 2.5 \\
\hline \multicolumn{6}{|l|}{ VI. Stress from teachers and nursing staff } \\
\hline Experience discrepancy between theory and practice & 9.8 & 25.4 & 45.9 & 17.2 & 1.6 \\
\hline $\begin{array}{l}\text { Do not know how to discuss patients' illness with teachers or } \\
\text { medical and nursing personnel }\end{array}$ & 10.7 & 34.4 & 36.9 & 15.6 & 2.5 \\
\hline $\begin{array}{l}\text { Feel stressed that teacher's instruction is different from one's } \\
\text { expectations }\end{array}$ & 9.8 & 29.5 & 37.7 & 19.7 & 3.3 \\
\hline Doctors lack empathy and are not willing to help & 13.1 & 32.8 & 30.3 & 18.9 & 4.9 \\
\hline Feel that teachers do not give afair evaluation of students. & 20.5 & 18.9 & 36.9 & 20.5 & 3.3 \\
\hline Lack of care and guidance from teachers & 19.7 & 27.9 & 32.0 & 17.2 & 3.3 \\
\hline
\end{tabular}

Most frequent types of stress from taking care of patients are lack of experience and ability in providing nursing care and in making judgment, the lack of knowledge regarding the possible ways to help patients with physio-physio-social concerns and concern about not being trusted or accepted by patients or patients' family. Half of the respondents agreed that sometimes they are not able to reach the level of satisfaction required by their customer. About $54.1 \%$ of the respondents have stated that they sometimes experience pressure from the nature and quality of clinical practice. Most of the respondents have stated that they feel pressure from teachers who evaluate student performance and they feel that clinical practice 
affects their involvement in extracurricular activities. Around $45.9 \%$ of the students sometimes experience discrepancy between theory and practice which results in stress from teachers and nursing staff.

Table 3: Descriptive Statistics of Coping Behaviour (n=122)

\begin{tabular}{|c|c|c|c|c|c|}
\hline & Never & Infrequently & Sometimes & Frequently & Always \\
\hline & $(\%)$ & $(\%)$ & $(\%)$ & $(\%)$ & $(\%)$ \\
\hline \multicolumn{6}{|c|}{ I. Avoidance } \\
\hline $\begin{array}{l}\text { To avoid difficulties } \\
\text { during clinical practice. }\end{array}$ & 22.1 & 17.2 & 38.5 & 18.9 & 3.3 \\
\hline To avoid teachers. & 44.3 & 13.9 & 26.2 & 14.8 & 0.8 \\
\hline $\begin{array}{l}\text { To quarrel with others } \\
\text { and lose temper. }\end{array}$ & 37.7 & 24.6 & 21.3 & 14.8 & 1.6 \\
\hline $\begin{array}{l}\text { To expect miracles, so } \\
\text { one does not have to } \\
\text { face difficulties. }\end{array}$ & 25.4 & 24.6 & 32.0 & 16.4 & 1.6 \\
\hline $\begin{array}{l}\text { To expect others to } \\
\text { solve the problem. }\end{array}$ & 27.0 & 22.1 & 27.9 & 19.7 & 3.3 \\
\hline To attribute to fate & 18.9 & 23.8 & 36.9 & 17.2 & 3.3 \\
\hline \multicolumn{6}{|c|}{ П. Problem Solving } \\
\hline $\begin{array}{l}\text { To adopt different } \\
\text { strategies to solve } \\
\text { problems }\end{array}$ & 2.5 & 11.5 & 40.2 & 32.8 & 13.1 \\
\hline $\begin{array}{l}\text { To set up objectives to } \\
\text { solve problems }\end{array}$ & 2.5 & 10.7 & 35.2 & 36.1 & 15.6 \\
\hline $\begin{array}{l}\text { To make plans, list } \\
\text { priorities, and solve } \\
\text { stressful events }\end{array}$ & 2.5 & 9.0 & 35.2 & 40.2 & 13.1 \\
\hline $\begin{array}{l}\text { To find the meaning of } \\
\text { stressful incidents. }\end{array}$ & 2.5 & 14.8 & 39.3 & 31.1 & 12.3 \\
\hline $\begin{array}{l}\text { To employ past } \\
\text { experience to solve } \\
\text { problems. }\end{array}$ & 3.3 & 6.6 & 42.6 & 29.5 & 18.0 \\
\hline $\begin{array}{l}\text { To have confidence in } \\
\text { performing as well as } \\
\text { senior schoolmates. }\end{array}$ & 2.5 & 12.3 & 39.3 & 30.3 & 15.6 \\
\hline \multicolumn{6}{|c|}{ III. Stay Optimistic } \\
\hline $\begin{array}{l}\text { To keep an optimistic } \\
\text { and positive attitude in } \\
\text { dealing with everything } \\
\text { in life }\end{array}$ & 1.6 & 8.2 & 30.3 & 30.3 & 29.5 \\
\hline To see things objectively. & 2.5 & 6.6 & 32.0 & 32.8 & 26.2 \\
\hline $\begin{array}{l}\text { To have confidence in } \\
\text { overcoming difficulties. }\end{array}$ & 1.6 & 9.8 & 32.8 & 36.1 & 19.7 \\
\hline $\begin{array}{l}\text { To cry, to feel moody, } \\
\text { sad, and helpless. }\end{array}$ & 16.4 & 18.9 & 36.9 & 18.0 & 9.8 \\
\hline
\end{tabular}




\begin{tabular}{|l|c|c|c|c|c|}
\hline \multicolumn{2}{|c|}{ IV. Transference } & 41.8 & & 23.8 \\
\hline $\begin{array}{l}\text { To feast and take a long } \\
\text { sleep. }\end{array}$ & 6.6 & 18.0 & 41.0 & 26.2 & 19.7 \\
\hline $\begin{array}{l}\text { To save time for sleep } \\
\text { and main tain good } \\
\text { health to face stress. }\end{array}$ & 1.6 & 11.5 & 34.4 & 31.1 & 23.0 \\
\hline $\begin{array}{l}\text { To relax via TV, } \\
\text { movies, a shower, or } \\
\text { physical exercises. }\end{array}$ & 2.5 & 9.0 & & & \\
\hline
\end{tabular}

It was seen that $44.3 \%$ stated that they never try to avoid teachers. More than $40 \%$ of the respondents sometimes adopt different strategies to solve problems and employ experience to solve problems. More than $30 \%$ of the respondents frequently try to keep an optimistic and positive attitude in dealing with everything in life, see things objectively and have confidence in overcoming difficulties. More than $40 \%$ of the respondents used feast and take a long sleep, try to save time for sleep and maintain good health to face stress and relax via TV, movies, a shower or physical exercise.

Table 4: Multiple Regression Results

\begin{tabular}{|l|l|l|l|l|l|l|l|l|l|l|l|l|}
\hline Module 1 & \multicolumn{3}{l}{ Module 2 } \\
\hline
\end{tabular}

In Model 1. Regression results provided in Table 4 showed that $48 \%$ of student's stress from peers, environment and daily life was explained by the constructs of problem-solving, avoidance and optimistic attitude. The result also showed significant relationship between avoidance and stress from peers, environment and daily life.

Model 2 show $22.7 \%$ of student's stress from taking care of patients was explained by the constructs of problem-solving, avoidance and stay optimistic attitude. The result also shows significant relationship between avoidance and stress from peers, environment and daily life.

Model 3 show $36.5 \%$ of student's stress from the assignment, workload and lack of professional skills was explained by the constructs of problem- 
solving, avoidance and stay optimistic. The result also shows a significant relationship between avoidance and stress from peers, environment and daily life.

\section{DISCUSSION}

The results of this study reported that most frequent types of stress from taking care of patients are lack of experience and ability in providing nursing care and in making judgment, the lack of knowledge regarding the possible ways to help patients with physio-physio-social concerns and concern about not being trusted or accepted by patients or patients' family. This discovery has also been found and proven by Labrageu (2013), where he was found that the emotional symptoms were the most common response to stress.

In the case of stress assignments and workload, $54.1 \%$ of the respondents have stated that they sometimes experience pressure from the nature and quality of clinical practice. According to Mahmoud et al., (2012), the existing strategies and programs primarily target students who are on academic level transitions where factor related to college were associated with these symptoms in this study and previous studies, is academic achievement. Kaur et al., (2009), has proven that the students were stressed because of too many assignments, long college hours, study overload, and restrictions in the college. It has also been proven by Abdullah Nahid \& Itedal, (2015), that the students were also worried about receiving poor marks and about their ability to provide nursing care and make judgments in their clinical practice.

In the case of stress due to lack of professional knowledge and skills, $44 \%$ of the respondents have stated that they are sometimes not familiar with medical history and terms. While $42.6 \%$ responded that they are unfamiliar with patients' diagnoses and treatments that are resulting in stress from lack of professional knowledge and skills. It showed similar result by Abdullah Nahid \& Itedal, (2015), where most of the stress seen by the students was the lack of knowledge and professional skills, when they were not familiar with medical terminology, or with patients' histories, diagnoses, and treatments. Only $18.9 \%$ of the respondents have stated that they are always familiar with the professional nursing skills. Several researchers such as Daengthern (2014), Singh, Sharma \& Sharma (2011); Al-Zayyat \& Al-Gamal (2014); Labrague (2013); Abdullah, Nahid \& Itedal (2015) also found that the factors causing stress among nursing students while in clinical practice, are due to the fact that both the knowledge and skills needed for patient care were inadequate.

Between the three items under environmental stress, $41.0 \%$ have stated that they sometimes feel stressed in the hospital environment where clinical practices take place. Among the 122 respondents, $23.8 \%$ frequently feel stressed from the rapid changes in patient's condition, and $32.4 \%$ are sometimes unfamiliar with the ward facilities. This situation has also been proven by Khater, Akhu-Zaheya, \& Shaban (2014), where factors related to having a stress level below the mean are due to environmental stress, stress of taking care of patients.

Several items were included in the questionnaire to identify the level of stress caused by peers and daily life. Among the four items, $48.4 \%$ of the respondents have stated that they experience competition from peers and clinical practice. The majority of the respondents have stated that they feel pressure from teachers who evaluate student performance and they feel that clinical practice affects their involvement in extracurricular activities. Wallace et al., (2015) found that students ranked their perceived stress level from clinical situations. One open-ended item asked students to describe their most stressful clinical experience.

Kaur et al., (2009) found that the students were stressed because of a relationship with fellow students. Ajibade et al. (2016), also found that the situation seems to develop stress among nursing students with poor inter-personal relations. About $45.9 \%$ of the students sometimes experience discrepancy between theory and practice which results in stress from teachers and nursing staff. It has been proven by Shiferaw, Anand \& Nemera (2015), that stress is related to the change of life, personal and work-related task and too many changes at one time, whether positive or negative, can overload the capacity of individuals to adapt successfully and cause diseases of one kind or other.

Kaneko \& Momino (2015) also found that stress factors related to clinical training where the students had only limited contact with clinical instructors or faculty members, and they felt stress because they could not contact their clinical instructors whenever they needed debriefing or guidance. The researcher found that the stress factor is similar to what had been shown by Abdullah, Nahid \& Itedal (2015), but the researcher has found some others factor which were relationships with teachers and clinical instructor, 
reflecting on patient-care experiences and healthcare staff and daily planning in clinical practice.

In order to manage the level of stress experienced by degree nursing students, this study has identified four coping behaviour. The first in the list is avoidance. About $44.3 \%$ stated that they never try to avoid teachers. This was proven by Wallace et al. (2015) study where the majority of subjects tend to use more healthy coping strategy compared with those negative unhealthy attitudes. More than $30 \%$ of the students have responded that they sometimes avoid difficulties during a clinical procedure, expect miracles, so one does not have to face difficulties and attribute to fate. Only $19.7 \%$ of the respondents frequently expect others to solve their problem. There is no doubt that there are $14.8 \%$ of degree nursing students, who frequently used avoid teachers and quarrel with others and lose temper as their coping strategy. This was proven by Shiferaw, Anand \& Nemera (2015), where they found that unhealthy coping strategies used by students regardless of ethnicity, marital status and education level.

According to Ajibade et al., (2016), students cannot avoid stress, but their ability to cope with stress is important in achieving success in academic achievement. So effectively management of stress and finding coping strategies in an appropriate manner is very important to prevent the negative effects of stress. In this study it was found that under the problem-solving mechanism, more than $40 \%$ of the respondents sometimes adopt different strategies to solve problems and employ experience to solve problems. About $40.2 \%$ stated that they frequently make plans, list priorities and solve stressful events. About $18 \%$ of the respondents employ experience to solve problems.

While the third coping behaviour is staying optimistic. Under these criteria, more than $30 \%$ of the respondents frequently try to keep an optimistic and positive attitude in dealing with everything in life, see things objectively and have confidence in overcoming difficulties and $36.9 \%$ of the students sometimes try to cry, feel moody, sad and helpless. This was proven by Abdullah, Nahid \& Itedal, (2015), where he found that nursing students even sometimes cry, feel irritable, sad and helpless.

Finally, a major portion of the respondents (more than $40 \%$ ) eat and take a long sleep, try to save time for sleep and maintain good health to face stress and relax via TV, movies, a shower or physical exercise. All these activities are included in Transference as a part of coping behaviour for stress. This was proven by Kaur et al. (2009), where they found that the students often used hobbies and leisure time activities such as listening to music, sleeping and watching TV, self-care such as praying to God and talking to self, seeking social support such as sharing and seeking help.

Multiple regressions was performed for three distinct models. Model 1. show $48 \%$ of student's stress were from peers, environment and daily life was explained by the constructs of problem-solving, avoidance and stay optimistic. The result also shows significant relationship between avoidance and stress from peers, environment and daily life. This study has been proven by Khan, Altaf, \& Kausar (2013) where the results found non-significant difference in the perceived stress between male and female students because female students have also learned the time management and stress coping strategies like male students.

Model 2 tested the relationship between independent variables and stress from taking care of patients. About 22.7 percent of student's stress were from taking care of patients was explained by the constructs of problemsolving, avoidance and stay optimistic. The result also shows significant relationship between avoidance and stress from peers, environment and daily life. This indicates that the application of various techniques as a stress coping behaviour is applied in a similar fashion by students from different age groups. This was proven by Khan, Altaf \& Kausar (2013), where academic stress was found to be higher in younger students than older students.

Model 3 tested the relationship between independent variables and stress from assignment, workload and lack of professional skills. It showed that $36.5 \%$ of student's stress from the assignment, workload and lack of professional skills was explained by the constructs of problem-solving, avoidance and stay optimistic. The result also shows a significant relationship between avoidance and stress from peers, environment and daily life. Problem solving and staying optimistic does not have a significant impact in coping with stress from taking care of patients

\section{CONCLUSION}

From outcomes, the most important factors in the stress for nursing students were related to coping with a new situation, such as staff nurses that show hostility, fail to give advice or teaching skill. So, more time must be devoted by the students for skills training to become 
knowledgeable. Therefore, nurse instructor/nurse supervisors must have good supervisory skills to support and assist students and have a positive attitude towards the nursing students. Environmental factors like change in learning environment and personal factors like problem of poor personal relations and wariness about family and academic factors are almost problems of all students.

\section{REFERENCES}

Abdullah, I.A., Nahid, K.E. \& Itedal, A.M. (2015). Factors associated with stress among nursing students (Najran University - Saudi Arabia). Journal of Nursing and Health Science (IOSR-JNHS), 4(6), pp 33-38.

Ajibade, B., Olabisi, O., Fabiyi, B., Ajao, O. \& Ayeni, A. (2016). Stress, Types of Stressors and Coping Strategies Amongst Selected Nursing Schools Students in South-West, Nigeria. European Journal of Biology and Medical Science Research, 4(3), pp 1-15.

Alzayyat, A. \& Al-Gamal, E. (2014). A review of the literature regarding stress among nursing students during their clinical education. International Council of Nurses, 61(3), pp 406-415.

Al-Zayyat, A.S. \& Al-Gamal, E. (2014). Perceived stress and coping strategies among Jordanian nursing students during clinical practicein psychiatric/mental health courses. International Journal of Mental Health Nursing, 23(4), pp 326-35.

Chan, C., So, W. \& Fong, D. (2009). Hong Kong Baccalaureate Nursing Students' Stress and Their Coping Strategies in Clinical Practice. Journal of professional nursing: official journal of the American Association of Colleges of Nursing, 25(5), pp 307-313.

Daengthern, L. (2014). Factor influencing stress among nursing students of faculty of nursing during clinical practice. The Journal of MacroTrends in Health and Medicine, 2(1), pp 61-71.

Goff, A.-M. (2011). Stressors, Academic Performance, and Learned Resourcefulness in Baccalaureate Nursing Students. International Journal of Nursing, 8(1).

Goff, A.M. (2011). Stressors, academic performance, and learned resourcefulness in baccalaureate nursing students. International Journal of Nursing Education Scholarship, 8: Article 1.

Kaneko, S. \& Momino, K. (2015). Stress Factors and Coping Behaviors in Nursing Students during Fundamental Clinical Training in Japan. International Journal of Nursing \& Clinical Practices, 2(138), pp 1-7.

Kaur, S., Das, K., Amrinder, S., Neha, K., Kanika, O. \& Sukhjit, L. (2009). Stress and coping in the nursing students. Journal of Mental Health \& Human Behavior, 14(1), pp 51-56.

Khan, M.J., Altaf, S. \& Kausar, H. (2013). Effect of Perceived Academic Stress on Students' Performance. FWU Journal of Social Sciences, 7(2), pp 146-151.

Khater, W.A., Akhu-Zaheya, L. \& Shaban, I.A. (2014). Sources of Stress and Coping Behaviours in Clinical Practice among Baccalaureate Nursing Students. International Journal of Humanities and Social Science, 4(6), pp 194-202.

Labrague, L. (2013). Stress, Stressors, and Stress Responses of Student Nurses in a Government Nursing School. Health Science Journal, 7(4), pp 424-435.

Lazarus, R.S. \& Folkman, S. (1984). Stress, appraisal, and coping. New York: Springer.

Mahmoud, J.S., Staten, R., Hall, L.A. \& Lennie, T.A. (2012). The Relationship among Young Adult College Students' Depression, Anxiety, Stress, Demographics, Life Satisfaction, and Coping Styles. Issues in Mental Health Nursing, 33(3), pp 149-156.

Rosenbaum, M. (1990). Foreword. In M. Rosenbaum (Ed.), Learned resourcefulness: On coping skills, self-control, and adaptive behavior (pp. xiv). New York: Springe. 
Selye, H. (1974). Stress without distress. New York: Lippincott.

Selye, H. (1976). The stress oflife. New York: McGraw-Hill.

Sheu, S., Lin, H. \& Hwang, S. (2002). Perceived stress and physio-psycho-social status of nursing students during their initial period of clinical practice: the effect of coping behaviors. International Journal of Nursing Studies, 39(2), pp 165-175.

Sheu, S., Lin, H., Hwang, S., Yu, P., Hu, W. \& Lou, M. (1997). The development and testing of perceived stress scale of clinical practice. Nursing Research, 5(4), 341-351.

Shiferaw, H.N., Anand, S. \& Nemera, G.N. (2015). Stress and Coping Strategies Among Generic B.Sc. Nursing Students of Jimma University, South West Ethiopia. International Journal of Recent Advances in Multidisciplinary Research,2(7), pp 511-517.

Singh, C., Sharma, S. \& Sharma, R.K. (2011). Level of stress and coping strategies used by nursing interns. Nursing and MidwiferyResearch Journal, 7(4), pp 152-160.

Wallace, L., Bourke, M.P., Tormoehlen, L.J. \& Poe-Greskamp, M.V. (2015). Perceptions of Clinical Stress in Baccalaureate Nursing Students. International Journal of Nursing Education Scholarship, 12(1), pp 1-8. 